\title{
Picramnia tumbesina: una nueva Picramniaceae, endémica del bosque seco tropical al occidente de Ecuador
}

\author{
Xavier Cornejo $^{1}$
}

Recibido en 1/03/2005. Aceptado en 16/09/2005

\begin{abstract}
RESUMEN - (Picramnia tumbesina: una nueva Picramniaceae, endémica del bosque seco tropical al occidente de Ecuador). Se describe Picramnia tumbesina, una nueva especie de árbol dioico, endémico del bosque seco tropical, al occidente del Ecuador. Esta es similar a $P$. sellowii Planch. subsp. sellowii, pero se distingue por presentar inflorescencias ramifloras, ramas fistulosas, hojas que alcanzan mayor dimensión, con grandes foliolos y pedicelos más largos en las flores pistiladas y frutos.
\end{abstract}

Palabras clave : Picramnia, endémica, bosque seco, Ecuador

\begin{abstract}
Picramnia tumbesina: a new Picramniaceae, endemic to the tropical dry forest in western Ecuador). Picramnia tumbesina a new dioecious tree, endemic to tropical dry forest in western Ecuador is described. It is similar to P. sellowii Planch. subsp. sellowii, but differs by having ramiflorous inflorescences, fistulose branches, larger leaflets and leaves, and longer pedicels on the pistillate flowers and fruits.
\end{abstract}

Key words: Picramnia, endemic, dry forest, Ecuador

\section{Introducción}

Picramnia Sw. es el género típico de la familia Picramniaceae (Fernando \& Quinn 1995), éste comprende unas 40 especies Neotropicales, distribuidas desde Florida hasta Brasil y Argentina (Thomas 1990; Pirani 2000; Thomas, com. pers.). En Ecuador siete especies han sido registradas (Jorgensen \& León 1999), principalmente en los bosques húmedos tropicales a ambos lados de los Andes hasta el bosque montano andino (obs. pers.).

Durante la fase de campo en el área del bosque seco de la región occidental, se encontró una especie con inflorescencias ramifloras y ramas fistulosas, los cuales son caracteres primarios en la identificación de las Picramnia (Thomas 1988; 1990; Pirani 1990; 1997; 2000). Esta es diferente de todas las demás especies conocidas de este género y es descrita a continuación.

Picramnia tumbesina X. Cornejo, sp. nov.

Species Picramnia sellowii Planch. subsp. sellowii affinis, a qua differt ramulis fistulosis; folia longioribus, (17-)30-41(-50) cm longis; lamina foliolis terminalis $13,5-18 \mathrm{~cm}$ longis; inflorescentiis ramifloris; floris pistillatis et fructus cum pedicellis longioribus,
1,5-5 $\mathrm{mm}$ et $12-18 \mathrm{~mm}$ longis; crescit in floresta decidua, bioregione tumbesina.

Tipo: ECUADOR. Prov. Guayas: Reserva Ecológica Manglares Churute, bosque seco tropical, 2²6'S, 79³8'W, 300-400 m, VI/1996 (fr.), C. Bonifaz \& X. Cornejo 3392 (holótipo GUAY [foto en QCA; fotocopias en COL, MO, NY, QCNE, WIS]; isótipo US).

Árbol dioico, hasta $8 \mathrm{~m}$ de alto, ca. $6 \mathrm{~cm}$ DAP, madera dura. Brotes tomentosos; ramas terminales inconspicuamente lenticeladas, tomentosas hasta tomentulosas, densamente cubiertas por una pubescencia erecta hasta adpresa, amarillenta, glabrescentes con la edad; ramas fistulosas. Estípulas supraxilares, tomentosas, 1-2,5 $\mathrm{mm}$. Hojas alternas, imparipinnadas, (17-)30-41(-50) cm de largo, 7-9folioladas; peciolo 1,8-4 cm, raquis 7-19 $\mathrm{cm}$, ambos tomentulosos; peciólulos 2-4×1-1,6 mm, tomentosos hasta tomentulosos; foliolos subopuestos hasta generalmente alternos, cartáceos, haz café-obscuro, lustroso, con margen tomentuloso, nervios sulcados hasta algo impresos, nervio medio denso hasta laxopiloso; envés café-claro hasta algo amarillento (debido a la pubescencia), lámina tomentulosa hasta más o menos denso-pilosa, bajo aumento, las bases de los

\footnotetext{
${ }^{1}$ Herbario GUAY, Universidad de Guayaquil, Av. 25 de Julio vía al Pto. Marítimo. Casilla 09-01-10634 Guayaquil-Ecuador (xcornejoguay@hotmail.com)
} 


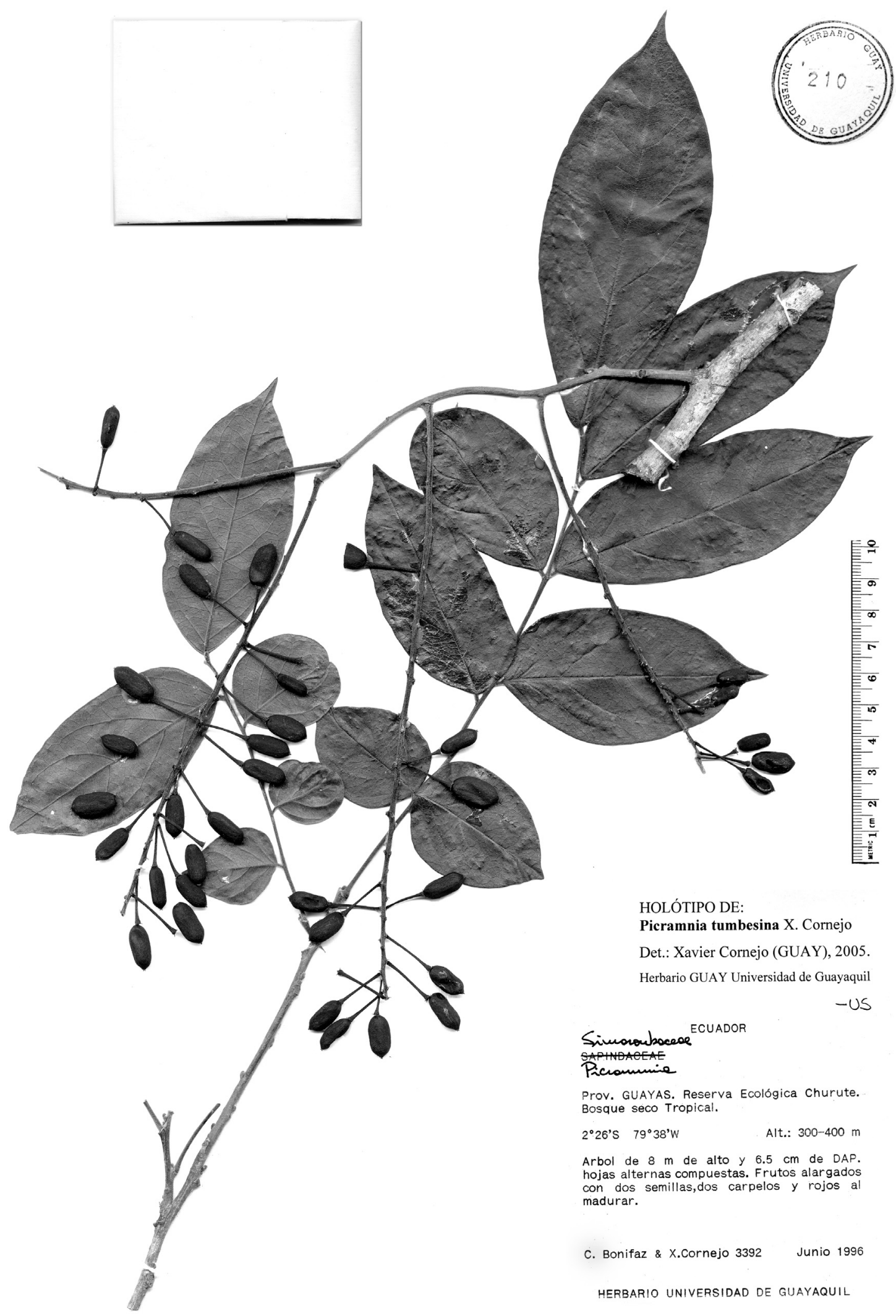

Figura 1. Picramnia tumbesina X. Cornejo: nótese la infructescencia ramiflora y los largos pedicelos de los frutos (C. Bonifaz \& X. Cornejo 3392). 
pelos se observan sobre la superficie de la lámina como puntos café-obscuros, nervios prominentes, tomentosos hasta tomentulosos; 5-8 pares de nervios laterales, algo arqueados hasta oblicuos, nervios terciarios reticulados, margen revoluto; foliolos terminales más desarrollados, elípticos, 13,5-1×5-6,2 $\mathrm{cm}$, ápice acuminado, base cuneada; foliolos laterales corto hasta oblongolanceolados o elípticos, 6-15,5×3,6-4,8 cm, ápice acuminado, base oblicua; foliolos basales amplioovados, 3-5×2,5-3,5 cm. Inflorescencias pistiladas en pleiotirsos, ramifloros y subterminales, (sub)pendulares, ca. $26 \mathrm{~cm}$ de largo, \pm tomentosos; pedúnculo primario ca. 1,5-2,5 cm, ráquis ca. $11 \mathrm{~cm}$, con 6-11 racimos de primer orden, entre $9-20 \mathrm{~cm}$, y raros racimos de segundo orden, todos subtendidos por una bráctea basal, linear, 1-2 mm, tomentosa en el lado abaxial, decidua. Flores dispuestas a lo largo de los racimos, solitarias o frecuentemente en fascículos de 2-5 flores y subtendidas por una bráctea común, de $1 \mathrm{~mm}$, tomentosa en el lado abaxial; pedicelos 1,5-5 mm, articulados en la base, usualmente cubiertos por una pubescencia \pm adpresa, densa a laxa, amarillenta, pocas veces glabros. Sépalos 5, libres, lanceolados, ca. $1 \times 0,3 \mathrm{~mm}$, ascendentes en la antesis, margen repando hasta crenado, verdosos, tomentosos a tomentulosos en el lado abaxial. Estaminodios 5, dispuestos en un segundo verticilo interno, alternisépalos, lineares, 0,4-0,7 mm, glabros. Ovario elipsoide, $1,5-2 \times 1 \mathrm{~mm}$, rojo-marrón en la antesis, glabro hasta laxo-piloso; lóculos 2. Estilo inconspicuo o ausente; estigma bífido, lóbulos lineares, fuertemente recurvados, cuyos ápices ocasionalmente tocan la parte superior del ovario, cada lóbulo 0,6-0,8 mm, densopapilosos, glabros hasta laxo-pilosos. Individuos y flores estaminadas desconocidas. Infructescencia ca. $26 \mathrm{~cm}$ de largo, pedicelos 12-18×0,8-1,1 mm, un poco dilatados en el ápice (ca. $2 \mathrm{~mm}$ ), con pubescencia laxa; fruto maduro oblongoide, $14-15 \times 6-7 \mathrm{~mm}$, rojo en vivo, negro al secar, en el ápice con corta y densa pubescencia adpreso-pilosa alrededor del estigma, el resto glabro; cáliz y estigma persistentes, estigma con lóbulos divergentes, en forma de "V", no fuertemente recurvados como cuando en flor, ca. 0,5 mm de largo; semillas 2.

Parátipos: ECUADOR. Prov. Guayas : Reserva Ecológica Manglares Churute, bosque seco tropical, 350 m, 28/XII/1991, fr., C. Cerón 17830 (QAP). Reserva Ecológica Andrade-Estación Científica Masvale, km 16, carretera Gnr. P. Montero-Puerto Inca, límite de la Reserva Manglares Churute, cerro Masvale-Churute, sendero La Cumbre, bosque seco tropical, 2²8'S, 7940'W, $200 \mathrm{~m}, 10 / \mathrm{VI} / 2003$, fl. 우, G. Villa et al. 2113 (GUAY, QCA).

Conocida únicamente del cerro Masvale, entre 200-400 m, el cual está compartido entre la Reserva Ecológica Manglares Churute y el vecino bosque privado de la Reserva Andrade, en la provincia del Guayas. Su zona de vida corresponde a bosque seco tropical, con vegetación decidua en estado secundario; crece sobre suelos básicos en la denominada bioregión tumbesina.

El patrón de distribución de Picramnia tumbesina es característico en Picramnia, género en el que aproximadamente la mitad de sus especies están restringidas a un área o son endémicas locales (Pirani 1988; 1989; Pirani \& Thomas 1988; Thomas 1988; 1990; 1997).

El nombre de esta nueva especie se refiere a la bioregión tumbesina, área de bosque seco tropical, deciduo, de la costa del Pacífico, localizada mayormente al occidente de Ecuador y que se extiende hasta la esquina noroccidental de Perú. Florece al inicio de la estación seca, durante los meses de mayo y junio; ha sido colectada con frutos maduros en junio y (hasta?) diciembre.

Por sus hojas pubescentes, tipo y longitud de las inflorescencias pistiladas, flores pistiladas y frutos, Picramnia tumbesina es similar y ha sido identificada como P. sellowii subsp. sellowii (Cerón 1996), distribuida en Brasil, Bolivia, Uruguay, Paraguay y norte de Argentina (Pirani 1997; 2000). Difiere morfológicamente de ésta por presentar inflorescencia ramiflora y subterminal $\times$ terminal; ramas fistulosas $\times$ no fistulosas; hojas de mayor dimensión, (17-)30-41(-50)× 14-23(-34) cm, con foliolos más grandes, el terminal $13,5-18 \times 6-10 \mathrm{~cm}$ de largo, lustrosos $\times$ opacos en el haz; flores pistiladas distintivamente pediceladas, con pedicelos más largos, entre 1,5-5 $\mathrm{mm} \times$ subsésiles, o con pedicelos hasta $2 \mathrm{~mm}$; y frutos con pedicelos más largos 12-18×4-10 mm.

Por sus ramas fistulosas, inflorescencias ramifloras y grandes foliolos, Picramnia tumbesina es similar a P. magnifolia Macbride, pero ésta última se diferencia principalmente por que presenta hojas con foliolos glabros, de textura coriácea, nervios terciarios percurrrentes, inflorescencias en racimos simples y frutos amplio-elípticos hasta globosos.

\section{Agradecimientos}

Al Dr. José Rubens Pirani, por sus útiles comentarios y la literatura provista sobre Picramnia. 
$\mathrm{Al}$ herbario QCA, especialmente al Blgo. Gorki Villa quien tuvo la gentileza de concederme su colección para el estudio. La foto del holótipo fue tomada por Kandis Elliot, artista del Departamento de Botánica de la Universidad de Wisconsin.

\section{Referencias bibliográficas}

Cerón, C.E. 1996. Diversidad, Especies Vegetales y Usos en la Reserva Ecológica Manglares-Churute, Provincia del Guayas-Ecuador. I.G.M. Revista Geográfica 36. Quito.

Fernando, E.S. \& Quinn, C.J. 1995. Picramniaceae, a new family, and a recircumscription of Simaroubaceae. Taxon 44(2): 177-181.

Jorgensen, P.M. \& León, S. (eds.). 1999. Catalogue of the Vascular Plants of Ecuador. Monographs in Systematic Botany from the Missouri Botanical Garden, 75, St. Louis.

Pirani, J.R. 1988. Uma nova espécie de Picramnia e notas sobre Picramnia campestris Rizz. \& Occh. (Simaroubaceae). Boletim de Botânica da Universidade de São Paulo 10: 7-13.
Pirani, J.R. 1989. Revisão Taxonômica de Picramnia (Simaroubaceae) no Brasil. Tese de Doutorado. São Paulo, Universidade de São Paulo.

Pirani, J.R. 1990. As espécies de Picramnia Sw. (Simaroubaceae) do Brasil: uma sinopse. Boletim de Botânica da Universidade de São Paulo 12: 115-180.

Pirani, J.R. 1997. Simaroubáceas. Pp. 22-32. In: A. Reis (ed.). Flora Ilustrada Catarinense, Parte I.

Pirani, J.R. 2000. Picramniaceae. Pp. 10-22. In: J.A. Rizzo (ed.). Flora dos Estados de Goiás e Tocantins, 26.

Pirani, J.R. \& Thomas, W.W. 1988. Duas novas espécies de Picramnia (Simaroubaceae) para a flora do norte do Brasil. Boletim do Museu Paranaense Emilio Goeldi, sér. Bot. 4: 271-280.

Thomas, W.W. 1988. A conspectus of Mexican and Central American Picramnia (Simaroubaceae). Brittonia 40(1): 89-105.

Thomas, W. 1990. A new species of Picramnia (Simaroubaceae) from Amazonian Peru. Britttonia 42(3): 171-174.

Thomas, W. 1997. A new species of Picramnia (Picramniaceae) from the Atlantic coastal forest of southern Bahia, Brazil. Brittonia 49(3): 380-383. 